\title{
La procreación humana. La sociología del aborto de Luc Boltanski
}

\author{
Matthias Bohlender ${ }^{1}$
}

Boltanski, Luc: Soziologie der Abtreibung: Zur Lage des fötalen Lebens. Frankfurt a. M., Suhrkamp, 2007, 541 páginas. ISBN-10: 3518584758 / ISBN-13: 9783518584750 .

Si se observan las preguntas y temas centrales de las Ciencias Sociales, resulta posible encontrar aquellas que principalmente se focalizan en las relaciones sociales que los hombres mantienen tanto entre sí como con los objetos externos. Así por ejemplo: cómo las personas crecen y son socializadas en la sociedad, cómo son reguladas y dominadas, cómo producen e intercambian sus productos, cómo y por qué luchan, pelean y matan, así como también, cómo argumentan, imaginan y legitiman sus acciones.

Ahora bien, todas estas preguntas presuponen algo importante y supuestamente natural: la constante procreación y reproducción de la especie humana. ¿Pero cómo son procreadas las personas? ¿Y cómo es posible descubrir la esencia que no logra ser procreada en tanto ser humano? Estas son justamente las dos preguntas que trabaja el libro de Luc Boltanski sobre "la situación de la vida fetal", el cual también puede ser titulado como una "sociología del aborto". Se trata de una obra larga y de varias facetas que analiza el fenómeno del aborto con los métodos de la lingüística estructural y de la sociología empírica, así como también de la historiografia y de la antropología social. En el centro de la investigación subyace la tesis respecto a que el aborto no representa el contrario de la reproducción, sino que éste en cierta medida está contenido en ella. El aborto aparece como el par inevitable de la reproducción, en cuanto ésta no es pensable ni practicable sin la posibilidad del aborto. Sólo cuando sabemos cómo son procreadas las personas en una sociedad, podemos averiguar algo sobre la constante normalidad y problemática del aborto.

Boltanski tematiza antes que nada aquello que él llama una gramática de la procreación, es decir, un modelo estructural a partir del cual él desarrolla los elementos cons-

\footnotetext{
${ }^{1}$ Doctor en Ciencia Política y docente de teoría política e historia de las ideas en la Humboldt-Universität zu Berlin (matthias.bohlender@sowi.hu-berlin.de).La traducción ha sido realizada por Cristóbal Rovira Kaltwasser. Las citas que aparecen en el siguiente texto son una traducción de la versión alemana de la obra de Boltanski aquí reseñada. ${ }^{2} \mathrm{El}$ autor de la recensión se basa en la traducción alemana del libro, la cual en alemán se titula como "Sociología del aborto: sobre la situación de la vida fetal” (Soziologie der Abtreibung: Zur Lage des fötalen Lebens). No obstante, la versión original francesa tiene un título distinto, a saber: "La condición fetal: Una sociología de la procreación y del aborto" (La condition foetale. Une sociologie de l'engendrement et de l'avortement).
} 
titutivos de nuestra concepción de la procreación. Mediante dicha gramática puede recién advertirse el lado empírico-fenomenológico e histórico-político del aborto.

Pero volvamos a la pregunta inicial del libro: ¿cómo son procreadas las personas? "Llamamos a una especie humana como completa [...] cuando ésta creación surge mediante la carne y a la vez surge desde la palabra. En este caso hablamos de una validación por medio de la palabra, la cual el hombre obtiene gracias a la carne" (p. 90). Boltanski parte del supuesto de esta dualidad entre carne y palabra, considerando esta premisa como la primera exigencia que pesa sobre la procreación y que a su vez determina nuestra comprensión sobre ella. A partir de esta dualidad se constituyen dos clases de especies y una operación central: tenemos todas aquellas especies que sólo son de carne y aquel conjunto de especies de carne que son confirmadas por la palabra. La operación consiste en la determinación, en el proceso de discriminación: desde un conjunto de sujetos de carne son confirmados sólo algunos mediante la palabra.

La máquina gramatical de Boltanski logra con la procreación simultáneamente la existencia del aborto: el no reconocimiento por parte de la madre. ¿Pero si el aborto es el otro lado de la moneda de la procreación, si en la confirmación siempre sucede también el rechazo, por qué tiene entonces el aborto una estatus social similar e igualmente ritualizado como la procreación? ¿A qué se debe que éste sea excluido de lo visible y lo ritualizable en toda sociedad y, por lo tanto, no se le otorgue ninguna función simbólica específica?

La respuesta la da Boltanski introduciendo en la gramática de la procreación una segunda premisa: "La segunda exigencia que nosotros a continuación queremos introducir y que somos de la opinión que es igual de determinante que la primera exigencia para la comprensión de la procreación, subraya que es imposible diferenciar las especies validadas mediante la carne de las especies validadas mediante la palabra, de modo tal que no es posible legitimar un tratamiento distinto para ambas especies" (p. 105). Es así como a la primera exigencia de discriminación se suma ahora una segunda exigencia de no discriminación. El aborto debe ser movido hacia lo privado, en cuanto no hay un criterio de distinción que pueda determinar por qué unos pueden ser eliminados, mientras que los otros sí pueden obtener un lugar en la especie humana.

En este punto, en el cual ambas exigencias son desarrolladas en tensión y como una contradicción, finaliza la gramática de la procreación y se transforma en una historiografia del aborto. A través de este giro busca Boltanski aquellas avenencias histórico-políticas y dispositivos sociales que sirven para aceptar, disminuir e incluso olvidar la contradicción ya indicada. 
En principio es posible encontrar una similitud central en todas estas avenencias. Ellas no pueden trascender la separación entre carne y palabra, aunque la pueden hacer lo suficientemente borrosa como para que dicha tensión disminuya. Todas las avenencias y dispositivos intentan reemplazar la precaria relación entre la reprobación y la confirmación del ser puesto en carne por otra alternativa; y dicha alternativa se llama "[...] la no procreación del ser o que éste sea engendrado bajo aquellas condiciones que garanticen su exclusividad" (p. 116). Ninguna procreación o si no la exclusiva engendración legítima de una nueva generación. Esta es la avenencia general que permite desdramatizar la tensión, la cual descansa en el vínculo existente entre sexualidad y procreación.

A continuación desarrolla el autor una perspectiva socio-histórica en torno a tres avenencias de carácter típico ideal, en las cuales se gesta una suerte de acople entre sexualidad y procreación así como también una instancia de legitimidad. Estas avenencias o dispositivos son tres: (1) la avenencia espiritual con el creador, (2) la avenencia familiar de parentesco y (3) la avenencia funcional con el Estado industrial.

En cada una de estas avenencias queda intacto el poder fáctico de la madre para la confirmación o el rechazo, tratándose entonces de un poder que nunca puede ser erradicado de forma cabal. No obstante, se requiere de una justificación social para ejercer este poder y aquella instancia que le otorga legitimación a la procreación se transforma de una avenencia en otra: desde dios para quien desde un comienzo todo ser de carne es igual y legítimo, pasando por el parentesco que en base al linaje distingue entre seres legítimos e ilegítimos, para finalizar en el moderno Estado industrial que solo acepta a aquellos seres que se puede esperar que cumplan un rol funcional al interior de la sociedad nacional. Sólo en esta última avenencia ocupan el mérito y la utilidad un rol dominante que puede ser observada en el acoplamiento entre procreación y sexualidad que tiene lugar en la ciencia y en profesiones específicas. Eugenesia, genética, demografia, estadística e incluso áreas de la economía se dedican a diagnosticar si el feto se merece ser reconocido. Es por ello que a contar de mediados del siglo XIX se puede detectar una política de la procreación que tiene por objeto la producción de una población de buena calidad y en un número balanceado.

Para Boltanski estos tres tipos históricos de avenencias se tornan evidentes cuando en los hacia los años 1970 acontecen dos cambios relevantes: la racionalización y diseminación de los métodos anticonceptivos así como también la amplia legalización del aborto. Después del ocaso de más de un siglo de la avenencia nacional-estatal constata Boltanski el surgimiento de una avenencia que él la llama como el proyecto parental. En base a una serie de entrevistas con personas afectadas, doctores y enfermeras y su propia teoría sobre "el nuevo espíritu del capitalismo" intenta especificar este nuevo régimen sexual y de procreación de mejor forma. ¿Qué o quién autoriza y legitima ahora la decisión de si una especie de carne debe ser validada o rechazada? ${ }^{3}$ Luc Boltanski y Eve Chiapello (2002): "El nuevo espíritu del capitalismo”. Madrid, Akal. 
$\mathrm{Ni}$ a dios ni a los parientes y menos aún al Estado le incumbe esta tarea."El proyecto describe aquí el acuerdo que une a un hombre y una mujer que tienen por objeto la obtención de un hijo" (p. 174). El proyecto de tener un hijo está cargado de un altísimo grado de reflexión y de voluntad de decisión. Nada debe quedar al alcance del azar; la contingencia debe ser minimizada o totalmente eliminada. En la planeación del proyecto se desarrolla todo por sí solo, como si cada desviación e irritación representara un impedimento para la singularidad y validación del futuro hijo. Así cita Boltanski una serie de sus entrevistas a mujeres que han abortado porque el futuro hijo habría sido un producto del azar: no era el momento oportuno, no era el hombre correcto, no se tenía la disposición adecuada, etc.

Pero el proyecto de tener un hijo no es solo un reflejo de procreación política del nuevo capitalismo, sino que es también un elemento resistente a sus efectos: corta temporalidad, fragmentación y dificultad para establecer vínculos. La decisión conciente, en contra de la brutal velocidad del ritmo de vida capitalista, de proyectar un hijo justamente requiere esta reflexividad, necesidad y - como acentúa Boltanski imaginación de que ahora se puede lograr la autenticidad de la vida. La enorme preocupación multimedial, caritativa y científica que hoy en día este proyecto obtiene desde la confirmación del feto no es sólo un producto de la medicina prenatal, sino que es también el resultado de este anhelo por autenticidad.

¿Pero cómo se concilia el aborto con esta nueva avenencia? ¿Cuál es el precio que se ahora se debe pagar? Antes existía el asesinato de niños y el abandono de los vástagos considerados como ilegítimos. En la nueva avenencia se está obligado a operar de una manera más dificil. Boltanski postula que ahora que el aborto está legalizado, éste se concilia sin grandes problemas con normalidad cuando es un aborto de algo inexistente; por ello habla él de una manipulación ontológica del feto.

Por consiguiente, este tipo de manipulación es necesaria para que en el marco de la avenencia basada en el proyecto de tener un hijo puedan ser distinguidas dos características diametralmente opuestas de las especies de carne: la inigualable existencia del feto cuando éste tiene espacio en el proyecto y su extrema desvalorización cuando no encuentra espacio. Se trata entonces de "separar lo más posible unas especies de otras" (p. 229), de manera que la incómoda pregunta por los criterios de selección para los validados y los eliminados sea suspendida. Para ello escoge Boltanksi los siguientes dos conceptos: el feto auténtico y el feto tumoral.

El feto auténtico es el portador del proyecto parental. "Apenas él se ha formado ya es un »bebé«" (p. 232).Y desde ahora emerge una gran avalancha de administración burocrática y científica - pasando por esoterismo y psicología vulgar - que se desenvuelve tanto sobre este ser como sobre sus progenitores. ¿Pero qué es lo que se sabe sobre el feto tumoral? Prácticamente nada. "En él debe ser invertida la más mínima imaginación posible, más allá del punto de que se trata de un tumor cuyo 
crecimiento sigue una lógica ciega y que debe ser extirpado" (p. 233). El completo dispositivo médico y social en torno al aborto - desde la recepción en el hospital, pasando por la anestesia, el despertar y la dada de alta, hasta llegar a los controles de rigor y el cobro del seguro médico - da la impresión de que uno ha sido sometido a una intervención terapéutica.

Sin embargo, Boltanski observa también en la nueva avenencia fisuras y puntos de ruptura. El quizás mayor problema para la nueva avenencia se gesta en el curso de su exigencia por autenticidad, la cual hace que el bebé diseñado en tanto proyecto deba ser llevado a carne a cualquier precio: con esto se hace referencia a los desarrollos tecnológicos que permiten la inseminación artificial. Es así como surgen aquellas nuevas especies que usualmente son llamadas como tecnofetos. Puesto que las especies engendradas mediante inseminación in vitro en el útero de la madre no pocas veces fallan, cada vez son engendradas más de estas especies y luego congeladas, para así posteriormente continuar haciendo intentos. Los tecnofetos no solo difuminan la frontera con el feto auténtico, sino que también dan origen a la siguiente pregunta: ¿dónde radica la diferencia en el trato instrumental entre ellos y los fetos tumorales? De tal manera, en la avenencia del proyecto parental subyace una inquietud no resuelta. La clara diferenciación entre el feto que no tiene precio y aquel sin valor pierde su nitidez y comienza a resolverse en las actuales disputas clasificatorias de tipo étnico, jurídico y político.

Si bien Boltanski al comienzo de su investigación se fijó como objetivo "el tratar al aborto como si fuera un objeto sociológico entre otros", llega al final a concluir que éste tiene un valor singular que va más allá de una sociología histórica del aborto y de la concepción. De la gramática ha surgido una antropología y de las obligaciones y contradicciones que conlleva la procreación se debe ahora no solo reconocer a la condición fetal, sino que también a la condición humana. A lo largo del libro se puede buscar este giro, primero cuando emerge el lingüista estructural para desprender las avenencias detectadas por el sociólogo histórico; este último se transforma a su vez en un fenomenólogo del aborto para así poder finalizar de forma consecuente en una antropología filosófica. Recién al final del libro queda en evidencia que Boltanski trata la pregunta del aborto y la cuestión de la inevitable fragilidad del hombre de la sociedad neocapitalista y de los peligros que están asociados con la posible desaparición de esta fragilidad. 